\title{
Relative versus absolute change in forced vital capacity in idiopathic pulmonary fibrosis
}

\author{
Luca Richeldi, ${ }^{1,2}$ Christopher J Ryerson, ${ }^{3}$ Joyce S Lee, ${ }^{2}$ Paul J Wolters, ${ }^{2}$ \\ Laura L Koth, ${ }^{2}$ Brett Ley, ${ }^{2}$ Brett M Elicker, ${ }^{4}$ Kirk D Jones, ${ }^{5}$ Talmadge E King Jr, ${ }^{2}$ \\ Jay H Ryu, ${ }^{6}$ Harold R Collard ${ }^{2}$
}

\begin{abstract}
- Additional materials are published online only. To view these files please visit the journal online (http://thorax.bmj. com/content/67/5.toc).

${ }^{1}$ Center for Rare Lung Diseases, University of Modena and Reggio Emilia, Modena, Italy ${ }^{2}$ Department of Medicine, University of California, San Francisco, California, USA ${ }^{3}$ Department of Medicine, University of British Columbia, Vancouver, Canada ${ }^{4}$ Department of Radiology, University of California, San Francisco, California, USA ${ }^{5}$ Department of Pathology, University of California, San Francisco, California, USA ${ }^{6}$ Department of Pulmonary and Critical Care Medicine, Mayo Clinic, Rochester, Minnesota, USA
\end{abstract}

\section{Correspondence to} Dr Luca Richeldi, Center for Rare Lung Diseases, University of Modena and Reggio Emilia, Policlinico Hospital, Via del Pozzo 71, 41100 Modena, Italy; luca.richeldi@unimore.it

LR and CJR contributed equally to this manuscript.

Received 1 October 2011 Accepted 1 March 2012 Published Online First 17 March 2012

\section{ABSTRACT}

Background Decline in forced vital capacity (FVC) over time reliably predicts mortality in patients with idiopathic pulmonary fibrosis. The use of this measure in clinical practice is recommended by current evidence-based guidelines. It is unknown if the method of calculating decline in FVC (relative vs absolute change) impacts its frequency or its ability to predict mortality.

Methods Patients with idiopathic pulmonary fibrosis from two prospective cohorts were included if they had a baseline and 12-month follow-up FVC. A $\geq 10 \%$ decline in FVC from baseline was calculated in two ways: a relative decline of $10 \%$ (eg, from $60 \%$ predicted to $54 \%$ predicted) and an absolute decline of $10 \%$ (eg, from $60 \%$ predicted to $50 \%$ predicted). The frequency of a $\geq 10 \%$ decline in FVC and its ability to predict 2-year transplantfree survival were compared between these two methods. Declines in FVC of $\geq 5 \%$ and $\geq 15 \%$ were similarly compared. Analyses were performed unadjusted and adjusted for age, gender, use of oxygen, baseline FVC and baseline diffusion capacity for carbon monoxide.

Results The frequency of any given FVC decline was significantly greater using the relative change in FVC method. For $\geq 10 \%$ decline, both methods predicted 2-year transplant-free survival with similar accuracy, and remained significant predictors after adjusting for baseline characteristics. The absolute change method appeared more predictive for $\geq 5 \%$ decline.

Conclusions Using the relative change in FVC maximises the chance of identifying $a \geq 10 \%$ decline in FVC without sacrificing prognostic accuracy. This may not hold true for $\geq 5 \%$ decline in FVC. These findings have important implications for clinical practice and the design of clinical trials.

\section{INTRODUCTION}

Serial change in forced vital capacity (FVC) is an accepted measure of the disease course in patients with idiopathic pulmonary fibrosis (IPF). ${ }^{1-7}$ FVC decline has been used as the primary endpoint in several randomised controlled drug trials, ${ }^{8-13}$ and the European Medicines Agency recently approved pirfenidone for use in patients with IPF based on studies using this endpoint. ${ }^{13} \mathrm{~A} \geq 10 \%$ decline in FVC has been reliably correlated with worse survival time in $\mathrm{IPF}^{1-5}$ and recent evidence-based guidelines recommend that an absolute decrease in $\mathrm{FVC}$ of $\geq 10 \%$ can be used as a surrogate marker of mortality. ${ }^{14}$ In addition, recent studies have

\section{Key messages}

What is the key question?

- Is the frequency of a decline in forced vital capacity (FVC) influenced by the method used to calculate the change in patients with idiopathic pulmonary fibrosis?

What is the bottom line?

- Using a relative (instead of an absolute) change in FVC maximises the chance of identifying $a \geq 10 \%$ decline without sacrificing prognostic accuracy.

\section{Why read on?}

- The choice of the method used to calculate a change over time in FVC has potential implications for both clinical practice and clinical trial design.

suggested that an FVC decline of $\geq 5 \%$ may also have clinical significance. ${ }^{15}$

$\mathrm{A} \geq 10 \%$ decline in $\mathrm{FVC}$ can be a relative decline of $10 \%$ (eg, from 4 to 3.6 litres or from $60 \%$ predicted to $54 \%$ predicted) or an absolute decline of $10 \%$ (eg, from $60 \%$ predicted to $50 \%$ predicted). Some clinical trials in patients with IPF have used the relative change from baseline in FVC (or VC), ${ }^{9}{ }^{15-17}$ while other clinical trials and cohort studies have used the absolute change from baseline. ${ }^{1-5} 810121318$ The frequency and predictive abilities of relative and absolute changes in FVC have not been directly compared.

The frequency and prognostic value of any given decline in FVC may depend on which method of calculation is used. Such differences would have important implications for clinical practice and clinical trial design. Consequently, we sought to evaluate how the method of calculation (relative vs absolute) impacted the frequency and prognostic value of declines in FVC in patients with IPF.

\section{METHODS \\ Patients}

Consecutive patients with a new diagnosis of IPF based on international guidelines ${ }^{19}$ were identified from two independent longitudinal cohorts at the University of California, San Francisco (UCSF) and the Mayo Clinic (Rochester, Minnesota, USA). 
Patients were included in the study if they had two serial FVC measurements 12 months apart. The Institutional Review Boards at each institution approved the protocol.

\section{Predictor and outcome variables}

The primary predictor variable was a $\geq 10 \%$ decline in FVC, defined as the difference between the baseline FVC and the 12 -month FVC ( \pm 3 months, figure 1$)$. The change in FVC was calculated as relative change $\left(\mathrm{FVC}_{\text {baseline }}-\mathrm{FVC}_{12}\right.$ months $/ \mathrm{FVC}_{\text {baseline, }}$ using either FVC in litres or \% predicted FVC) and absolute change ( $F_{\text {b }}$ baseline $-F_{12}$ months, using \% predicted FVC). Since the two methods of calculating relative change are mathematically equivalent, we only report the data from relative change in \% predicted FVC (data for the relative change in FVC in litres is included in table 1 in the online data supplement). Secondary analysis included the predictor variable of $\geq 5 \%$ and $\geq 15 \%$ declines in FVC. Additional predictor variables included were age, gender, oxygen use, FVC and diffusion capacity for carbon monoxide (DLCO). FVC and DLCO were measured according to previous guidelines ${ }^{20} 21$ and \% predicted FVC was recalculated from the raw data using the National Health and Nutrition Examination Survey (NHANES) equation. ${ }^{22}$

The primary outcome was 2-year transplant-free survival, defined as the absence of death or lung transplant at 2 years measured from the date of the 12-month FVC (ie, 2 years after the change in FVC was observed). Secondary outcomes included survival at 2 years, transplant-free survival at 1 year, survival at 1 year, time to death or lung transplant, and time to death. For survival outcomes, lung transplant was either not considered an event (survival at 2 years, survival at 1 year) or subjects were censored on the date of transplant (time to death). Vital status and transplantation status were determined from review of the medical record and use of the Social Security Death Registry (accessed on 27 Jun 2011 at http://ssdi.rootsweb.ancestry.com).

\section{Statistical analysis}

The frequency of decline in FVC was determined for both methods and compared using McNemar's $\chi^{2}$ test (test of symmetry). The impact of baseline FVC on frequency of decline in FVC was evaluated by considering baseline FVC as a continuous variable and by stratifying baseline FVC above or below the median value. Logistic regression was used to determine the association of dichotomised decline in FVC with 2-year transplant-free survival. Unadjusted analyses were performed, followed by adjustment for age, gender, oxygen use and baseline $\%$ predicted FVC and DLCO. The utility of adding change in FVC to the nested baseline variables was tested using a like-

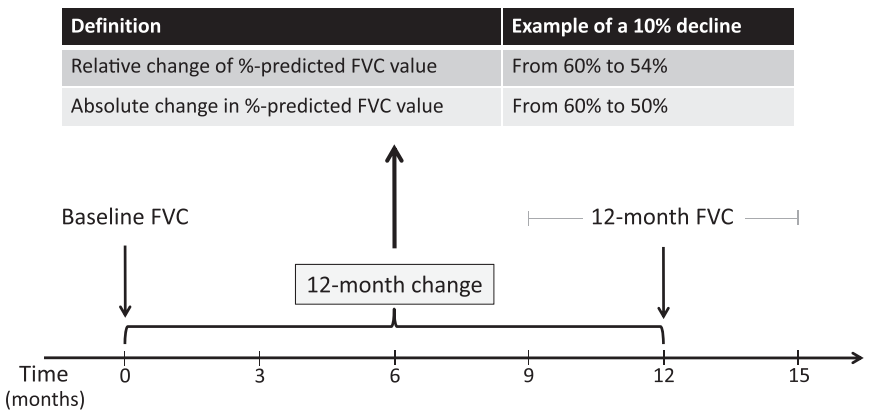

Figure 1 Methods of 12-month decline in forced vital capacity (FVC) calculation. Two methods of calculating change in FVC over 12 months were used. The time interval for 12-month follow-up FVC was set at $9-15$ months to allow for adequate numbers of patients. lihood ratio test. These analyses were repeated for secondary endpoints (logistic regression and Cox proportional hazards). The predictive ability of each method was compared using OR or HRs and the area under the receiver operating characteristic (AUROC) curve or c-statistic as appropriate. We compared test characteristics subjectively since there is no formal means to directly compare these non-nested models. Analyses were repeated excluding patients with severe disease by physiological criteria (FVC $<50 \%$ or DLCO $<35 \%$ predicted). All data analysis was performed using Stata V.11.0 (Stata Corp).

\section{RESULTS}

\section{Patient population}

A total of 142 patients were included in the primary analysis (88 from UCSF and 54 from Mayo Clinic, table 1). Included patients did not differ in baseline characteristics or survival from those excluded due to lack of a 12-month follow-up FVC ( $n=189$; data not shown). The mean age at the time of diagnosis was 67 years, most patients were men with a history of smoking, and more than half had surgical lung biopsy. The mean FVC at baseline was 2.7 litres (68\% predicted) and mean DLCO was $12.4 \mathrm{ml} /$ $\mathrm{min} / \mathrm{mm} \mathrm{Hg}$ (49\% predicted). Patients had a wide range of disease severity, with a broad distribution of baseline FVC and DLCO (see figure 1 in the online data supplement). There were 108 patients that met physiological inclusion criteria commonly used for intervention studies (FVC $\geq 50 \%$ predicted and DLCO $\geq 35 \%$ predicted).

\section{Frequency of decline in FVC over 12 months}

The frequency of $\mathrm{a} \geq 10 \%$ decline in FVC over 12 months was almost twice as high using the relative change in FVC than using the absolute change in FVC $(30 \%$ vs $18 \%, \mathrm{p}<0.001)$ (table 2$).$ There was no significant relationship between baseline FVC and the prevalence of $\geq 10 \%$ decline in FVC over 12 months using either method (see table 2 and figure 2 in the online data supplement). The results were similar for $5 \%$ and $15 \%$ declines in FVC and when excluding patients with severe disease (table 2).

Baseline patient characteristics were not different when comparing patients without $\mathrm{a} \geq 10 \%$ decline in FVC by either method ( $n=99)$, patients with a $\geq 10 \%$ decline only by the relative method $(n=17)$, and patients with decline by both methods ( $\mathrm{n}=26)$ (data not shown). Median transplant-free survival was 4.7 years for patients without a $\geq 10 \%$ decline in FVC by either method, 2.6 years for patients with a $\geq 10 \%$ decline only by the relative method, and 2.0 years for patients with $a \geq 10 \%$ decline by both methods ( $p$ value $=0.001$ for the difference between all groups).

Table 1 Baseline patient characteristics ( $n=142$ )

\begin{tabular}{ll}
\hline Characteristic & Mean (SD) or \% \\
\hline Age & $67.0(9.0)$ \\
Male gender & $74 \%$ \\
History of smoking & $69 \%$ \\
Currently smoking & $1.4 \%$ \\
Biopsy proven disease & $56 \%$ \\
Current or previous prednisone use & $35 \%$ \\
Long-term oxygen therapy & $19 \%$ \\
FVC, litres & $2.70(0.78)$ \\
FVC, \% predicted & $67.6(16.1)$ \\
DLCO (ml/min/mm Hg) & $12.4(4.2)$ \\
DLCO, \% predicted & $48.5(15.1)$ \\
\hline
\end{tabular}

DLCO, diffusion capacity for carbon monoxide; FVC, forced vital capacity. 
Table 2 Frequency of $\geq 5 \%$, $\geq 10 \%$ and $\geq 15 \%$ decline in FVC at 12 months

\begin{tabular}{llll}
\hline & \multicolumn{2}{l}{ 12-month FVC decline } & \\
\cline { 2 - 4 } Method of calculation & $\mathbf{2 5 \%}$ & $\mathbf{1 0 \%}$ & $\mathbf{1 0 \%}$ \\
\hline $\begin{array}{l}\text { Whole cohort }(\mathrm{n}=142) \\
\text { Relative change }\end{array}$ & $70(49.3)$ & $43(30.3)$ & $30(21.1)$ \\
$\begin{array}{l}\text { Absolute change } \\
\mathrm{p} \text { Value for difference }\end{array}$ & $52(36.6)$ & $26(18.3)$ & $11(7.7)$ \\
between methods & $<0.001$ & $<0.001$ & $<0.001$ \\
$\begin{array}{l}\text { Excluding patients with severe disease }(\mathrm{n}=108)^{*} \\
\text { Relative change }\end{array}$ & $58(53.7)$ & $36(33.3)$ & $25(23.2)$ \\
$\begin{array}{l}\text { Absolute change } \\
\mathrm{p} \text { Value for difference } \\
\text { between methods }\end{array}$ & $46(42.6)$ & $22(20.4)$ & $7(6.5)$ \\
\hline
\end{tabular}

Data presented as number of patients (\% of patients) meeting the stated threshold.

*Patients were excluded from this analysis if baseline FVC $<50 \%$ or DLCO $<35 \%$.

DLCO, diffusion capacity for carbon monoxide; FVC, forced vital capacity.

\section{Predictive value of decline in FVC over 12 months}

Both methods of calculating $\geq 10 \%$ decline in FVC predicted transplant-free survival at 2 years, using both unadjusted and adjusted analysis (table 3 and figure 2). The adjusted ORs for death or transplant at 2 years were 3.39 (95\% CI 1.14 to 10.07$)$ for the relative method and 4.52 (95\% CI 1.27 to 16.12) for the absolute method, with overlapping CIs. Using the relative or absolute method, the AUROC was 0.82 with the addition of $\geq 10 \%$ decline in FVC to the baseline variables age, gender, oxygen use, $\%$ predicted FVC and \% predicted DLCO. The addition of $\geq 10 \%$ FVC decline to baseline variables significantly improved model performance for both the relative and absolute methods (likelihood ratio test $p$ value $=0.02$ for both methods). $\mathrm{A} \geq 5 \%$ decline in FVC over 12 months predicted a greater risk of death or transplant at 2 years on adjusted analysis using only the absolute method of calculation (table 3). Adjustment for each individual covariate (age, gender, oxygen use, baseline FVC and baseline DLCO) increased the OR of death or transplant at 2 years. The greatest increase in OR was seen with the adjustment for baseline FVC. A $\geq 15 \%$ decline in FVC over 12 months predicted a greater risk of death or transplant at 2 years on unadjusted and adjusted analysis using only the relative method of calculation (table 3). The results were qualitatively similar for all secondary outcomes, including the direction and magnitude of the effect (OR and HRs; see tables 3-5 in the online data supplement), and the overall predictive accuracy of the models (AUROC curve and c-statistic; data not shown). The results were also similar for all analyses when excluding patients with severe disease (table 3).

\section{DISCUSSION}

Recent evidence-based guidelines for the management of IPF state that an absolute decline in FVC of $\geq 10 \%$ over time is an

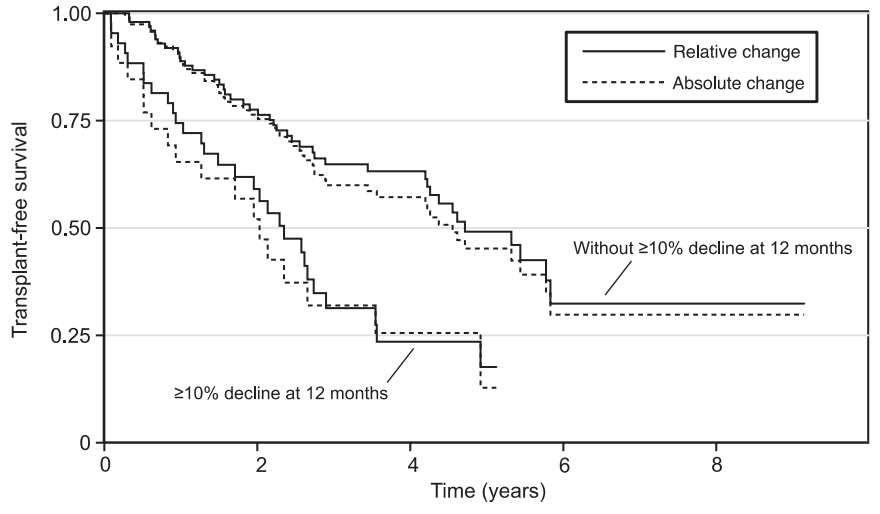

Figure 2 Transplant-free survival estimates based on $\geq 10 \%$ decline in forced vital capacity (FVC). Kaplan-Meier survival estimates for transplant-free survival are shown for both methods comparing subjects with and without $a \geq 10 \%$ decline in FVC at 12 months. Solid lines represent absolute change in \% predicted FVC and dashed lines represent relative change in $\%$ predicted FVC. Patients with a relative decline in FVC of $\geq 10 \%$ had a median transplant-free survival of 2.35 years $(95 \% \mathrm{Cl} 1.49$ to 2.90$)$ compared with 4.71 years $(95 \% \mathrm{Cl} 4.20$ to 5.83 ) for those without a $10 \%$ relative decline in FVC. Patients with an absolute decline in FVC of $\geq 10 \%$ had a median transplant-free survival of 2.03 years (95\% Cl 0.83 to 3.55$)$ compared with 4.55 years $(95 \% \mathrm{Cl} 2.90$ to 5.77 ) for those without a $10 \%$ absolute decline in FVC.

acceptable method to assess disease progression and estimate risk of future mortality in patients with IPF. ${ }^{14}$ As a consequence, $\mathrm{a} \geq 10 \%$ decline in FVC affects management decisions (eg, enrolment in a clinical trial, start of a therapy, referral for lung transplant evaluation) and the counselling of patients. Our results show that the method used to calculate change in FVC has a significant impact on the frequency of a decline in FVC over 12 months in patients with IPF, and suggest that $a \geq 10 \%$ relative decline in FVC may be preferable to an absolute $\geq 10 \%$ decline in assessing disease progression.

The choice of method has potential implications for both clinical practice and clinical trial design. Clinically, the use of the absolute method to calculate $a \geq 10 \%$ decline in FVC fails to identify almost half of patients with a $\geq 10 \%$ decline in FVC calculated using the relative method. These 'relative-method positive, absolute-method negative' patients had a similar 2-year transplant-free survival to patients with a $\geq 10 \%$ decline by both methods. This suggests that using the absolute method to calculate $\geq 10 \%$ decline in FVC will miss some patients that have a clinically meaningful decline in FVC, which could lead to delays in important management decisions.

Our findings also demonstrate the potential impact of the method used to calculate $\mathrm{a} \geq 10 \%$ decline in FVC on the design and results of clinical trials. Almost twice as many patients

Table 3 Relationship between decline in FVC at 12 months and transplant-free survival at 2 years

\begin{tabular}{|c|c|c|c|c|c|c|}
\hline \multirow[b]{2}{*}{ Method of calculation } & \multicolumn{2}{|c|}{ 12-month FVC decline of $\geq 5 \%$} & \multicolumn{2}{|c|}{ 12-month FVC decline of $\geq 10 \%$} & \multicolumn{2}{|c|}{ 12-month FVC decline of $\geq 15 \%$} \\
\hline & $\overline{\mathrm{OR}(95 \% \mathrm{CI})}$ & Adjusted $\mathrm{OR}^{*}(95 \% \mathrm{Cl})$ & $\overline{O R}(95 \% \mathrm{CI})$ & Adjusted $\mathrm{OR}^{*}(95 \% \mathrm{Cl})$ & $\overline{\mathrm{OR}(95 \% \mathrm{CI})}$ & Adjusted $\mathrm{OR}^{*}(95 \% \mathrm{CI})$ \\
\hline \multicolumn{7}{|l|}{ Whole cohort $(n=142)$} \\
\hline Absolute change & 2.04 (0.93 to 4.48$)$ & $5.21(1.64$ to 16.60$)$ & $3.10(1.22$ to 7.89$)$ & $4.52(1.27$ to 16.12$)$ & $3.00(0.85$ to 10.53$)$ & $1.75(0.33$ to 9.40$)$ \\
\hline \multicolumn{7}{|c|}{ Excluding patients with severe disease $(n=108) \dagger$} \\
\hline Relative change & 2.41 (0.87 to 6.66$)$ & $2.58(0.77$ to 8.60$)$ & $2.40(0.90$ to 6.43$)$ & 2.51 (0.75 to 8.33$)$ & $4.32(1.50$ to 12.45$)$ & $4.71(1.26$ to 17.66$)$ \\
\hline
\end{tabular}

*Adjustment for gender and baseline age, oxygen use, FVC and DLCO

†Patients were excluded from this analysis if baseline FVC $<50 \%$ or DLCO $<35 \%$.

DLCO, diffusion capacity for carbon monoxide; FVC, forced vital capacity. 
Figure 3 Impact of method of calculating decline in forced vital capacity (FVC) on sample size estimates. Sample size requirements were determined for both methods of calculating change in FVC for a clinical trial using $\geq 10 \%$ decline in FVC as a primary endpoint. Sample size estimates are based on a head-tohead comparison of two therapies, with a baseline decline in FVC of equal frequency and variance compared with our cohort. Samples size estimates are provided for three different effect sizes $(20 \%$ relative difference $=0.2,35 \%$ relative difference $=0.35$ and $50 \%$ relative difference $=0.5)$, and two different power levels $(80 \%=$ black bar, $90 \%=$ black plus grey bar).

would be required to adequately power a clinical trial to $\geq 10 \%$ decline in FVC using the absolute method than using the relative method (figure 3). Put another way, using the relative method to calculate $\geq 10 \%$ decline in FVC would substantially increase the number of events in such a trial, reducing sample size requirements and increasing feasibility. In theory, trials that used a $\geq 10 \%$ decline in FVC as part of their primary endpoint (eg, as a component of progression-free survival) could yield different results depending on the choice of relative or absolute method. This difference between methods applies to our cohort as a whole and to the subgroup of patients with less severe disease who would meet the inclusion criteria for the most recent randomised clinical trials.

Recently, it has been reported that declines in FVC smaller than $10 \%$ predict mortality. ${ }^{15}$ Unlike our findings for a $\geq 10 \%$ decline in FVC, we found that $\mathrm{a} \geq 5 \%$ decline in FVC over 12 months was predictive of 2-year transplant-free survival only when calculated as an absolute change, and only when adjusting for baseline variables. This apparent difference between our study and previous studies may be due to different study populations. Specifically, previous studies showing that small declines in FVC are predictive of mortality have limited the number of patients with severely reduced baseline FVC by either requiring surgical lung biopsy for diagnosis, or by excluding patients with severe disease. $^{15}$ In our study, the most powerful modifier of the predictive power of a relative $5 \%$ decline in FVC was baseline FVC, suggesting that baseline severity may be an important factor in evaluating the significance of small changes in FVC. This suggests that for clinicians and clinical researchers who decide to use declines of $<10 \%$, the absolute method may be more appropriate. This may be due to an increased risk of identifying random, clinically insignificant fluctuations in FVC using the relative method. Interestingly, we found that $\mathrm{a} \geq 15 \%$ decline in FVC over 12 months was predictive of 2 -year transplant-free survival only when calculated as a relative change. However, the lack of statistical significance for the absolute change is likely related to the small number of events when using this method.

Our results are limited by the retrospective nature of the study design; not all patients had an FVC measurement recorded 12 months after initial evaluation. Importantly, there were no significant clinical or physiological differences between those patients who had a 12-month follow-up FVC measurement and those patients who did not (data not shown). A second limitation is that the numbers of patients with relatively normal or with severely reduced pulmonary function were small, and thus our results may not apply to all patients with IPF. However, the findings of this study do not appear to change with stratification or adjustment for baseline FVC. Finally, our results are appli- cable to a 12-month change in FVC, but may not apply to other intervals of change. We chose to evaluate a 12-month change in FVC primarily because change in FVC over 12 months is commonly reported in clinical trials. An additional advantage of using a 12-month interval is that every individual will age exactly 1 year. This eliminates distortion in \% predicted FVC values that would occur with other time intervals in which only some individuals would have a birthday that resulted in ageing-related change in their predicted FVC. This birthday phenomenon would not affect change in FVC reported in litres.

In summary, this study demonstrates that the method used to calculate change in FVC in patients with IPF is important as it affects the frequency of any given decline in FVC, the most commonly used measure of disease progression in clinical practice and clinical trials. We believe that clinicians and clinical researchers should consider using the relative change in FVC when calculating a $\geq 10 \%$ decline in FVC. This approach maximises the chances of identifying clinically meaningful change without sacrificing prognostic accuracy.

Acknowledgements The authors wish to acknowledge the assistance of Sally McLaughlin and Jane Berkeley for their efforts in caring for many of these patients and their assistance with managing the clinical data. We would also like to acknowledge the providers in the community for partnering with us in the care of patients with IPF and referring patients to our centres for participation in clinical research. Finally, we would like to acknowledge the patients and family members whose generosity and selflessness in participating in research makes progress possible.

Contributors Conception and design: LR, CJR, HRC; analysis and interpretation: $L R$ CJR, JSL, PJW, LLK, TEK, HRC; drafting the manuscript for important intellectual content: LR, CJR, JSL, PJW, LLK, BL, BME, KDJ, TEK, JHR, HRC.

Funding $\mathrm{NIH}$ grant $\mathrm{HL} 086516$ (HRC).

Correction notice This article has been corrected since it was published online first. The author names now read Brett Ley and Brett M Elicker. The following sentence has been updated to read: 'The mean age at the time of diagnosis was 67 years, most patients were men with a history of smoking, and more than half had surgical lung biopsy.'

Competing interests None to declare.

Patient consent Obtained.

Ethics approval Ethics committee of UCSF and Mayo Clinic.

Provenance and peer review Not commissioned; externally peer reviewed.

\section{REFERENCES}

1. Zappala CJ, Latsi PI, Nicholson AG, et al. Marginal decline in forced vital capacity is associated with a poor outcome in idiopathic pulmonary fibrosis. Eur Respir $J$ 2010;35:830-6.

2. Flaherty KR, Mumford JA, Murray S, et al. Prognostic implications of physiologic and radiographic changes in idiopathic interstitial pneumonia. Am J Respir Crit Care Med 2003;168:543-8. 
3. Collard HR, King TE Jr, Bartelson BB, et al. Changes in clinical and physiologic variables predict survival in idiopathic pulmonary fibrosis. Am J Respir Crit Care Med 2003;168:538-42.

4. King TE Jr, Safrin S, Starko KM, et al. Analyses of efficacy end points in a controlled trial of interferon-gamma1b for idiopathic pulmonary fibrosis. Chest 2005;127:171-7.

5. du Bois RM, Weycker D, Albera C, et al. Ascertainment of individual risk of mortality for patients with idiopathic pulmonary fibrosis. Am J Respir Crit Care Med 2011;184:459-66

6. Martinez FJ, Safrin S, Weycker D, et al. The clinical course of patients with idiopathic pulmonary fibrosis. Ann Intern Med 2005;142:963-7.

7. Latsi PI, du Bois RM, Nicholson AG, et al. Fibrotic idiopathic interstitial pneumonia: the prognostic value of longitudinal functional trends. Am J Respir Crit Care Med 2003;168:531-7.

8. Raghu G, Brown KK, Bradford WZ, et al. A placebo-controlled trial of interferon gamma-1b in patients with idiopathic pulmonary fibrosis. $N$ Engl $\mathrm{J}$ Med 2004:350:125-33.

9. Demedts $\mathbf{M}$, Behr J, Buhl R, et al. High-dose acetylcysteine in idiopathic pulmonary fibrosis. N Engl J Med 2005;353:2229-42.

10. King TE Jr, Behr J, Brown KK, et al. BUILD-1: a randomized placebo-controlled trial of bosentan in idiopathic pulmonary fibrosis. Am J Respir Crit Care Med 2008;177:75-81.

11. Raghu G, Brown KK, Costabel U, et al. Treatment of idiopathic pulmonary fibrosis with etanercept: an exploratory, placebo-controlled trial. Am J Respir Crit Care Med 2008;178:948-55.

12. Daniels CE, Lasky JA, Limper AH, et al. Imatinib treatment for idiopathic pulmonary fibrosis: randomized placebo-controlled trial results. Am J Respir Crit Care Med 2010;181:604-10.
13. Noble PW, Albera C, Bradford WZ, et al. Pirfenidone in patients with idiopathic pulmonary fibrosis (CAPACITY): two randomised trials. Lancet 2011;377:1760-9.

14. Raghu G, Collard HR, Egan JJ, et al. An official ATS/ERS/JRS/ALAT statement: idiopathic pulmonary fibrosis: evidence-based guidelines for diagnosis and management. Am J Respir Crit Care Med 2011;183:788-824.

15. Taniguchi H, Ebina $\mathrm{M}$, Kondoh $\mathrm{Y}$, et al. Pirfenidone in idiopathic pulmonary fibrosis Eur Respir J 2010;35:821-9.

16. Azuma A, Nukiwa T, Tsuboi E, et al. Double-blind, placebo-controlled trial of pirfenidone in patients with idiopathic pulmonary fibrosis. Am J Respir Crit Care Med 2005;171:1040-7.

17. King TE Jr, Brown KK, Raghu G, et al. BUILD-3: a randomized, controlled trial of bosentan in idiopathic pulmonary fibrosis. Am J Respir Crit Care Med 2011:184:92-9.

18. King TE Jr, Albera C, Bradford WZ, et al. Effect of interferon gamma-1b on survival in patients with idiopathic pulmonary fibrosis (INSPIRE): a multicentre, randomised, placebo-controlled trial. Lancet 2009;374:222-8.

19. American Thoracic Society. Idiopathic pulmonary fibrosis: diagnosis and treatment. International consensus statement. American Thoracic Society (ATS), and the European Respiratory Society (ERS). Am J Respir Crit Care Med 2000:161:646-64.

20. Macintyre N, Crapo RO, Viegi G, et al. Standardisation of the single-breath determination of carbon monoxide uptake in the lung. Eur Respir J 2005;26:720-35.

21. Miller MR, Hankinson J, Brusasco V, et al. Standardisation of spirometry. Eur Respir J 2005;26:319-38.

22. Hankinson JL, Odencrantz JR, Fedan KB. Spirometric reference values from a sample of the general U.S. population. Am J Respir Crit Care Med 1999;159:179-87.

\section{Thorax alerts}

Sign up for our electronic table of contents alerts and you will never miss new issues of Thorax when published online. Stay ahead and up to date by visiting thorax.bmj.com. 